\title{
Controlling Brown Spot of Pear by a Synthetic Antimicrobial Peptide Under Field Conditions
}

Mireia Puig, Concepció Moragrega, Lídia Ruz, Emilio Montesinos, and Isidre Llorente, Institute of Food and Agricultural TechnologyXaRTA-CIDSAV, University of Girona, Spain

\begin{abstract}
Puig, M., Moragrega, C., Ruz, L., Montesinos, E., and Llorente, I. 2015. Controlling brown spot of pear by a synthetic antimicrobial peptide Under field conditions. Plant Dis. 99:1816-1822.

Brown spot of pear, caused by Stemphylium vesicarium, is a fungal disease of increasing importance in several pear-growing areas of Europe. Disease control measures include the application of fungicides and sanitation methods. Antimicrobial peptides may be a complement or alternative to conventional fungicides used to manage brown spot disease. In a previous study, the synthetic peptide BP15 showed postinfection fungicidal activity against $S$. vesicarium in in vitro and detached-leaf assays. In the present study, the efficacy of BP15 (KKLFKKILKVL-NH $\mathrm{N}_{2}$ ) in controlling brown spot of pear was evaluated under field conditions

using potted plants and pear trees in orchards. In field trials, the treatments with BP15 or with the fungicide thiram were scheduled according to the infection risk predicted by the BSPcast model. Potted pear plants treated with BP15 showed a disease reduction of about 42 to $60 \%$ in five of seven trials. In three of four tree trials, the disease severity on shoots treated with BP15 was significantly lower than in the nontreated controls, with a mean efficacy of $38.2 \%$. It was concluded that BP15 is a good candidate to be further developed as a fungicide for controlling brown spot of pear.
\end{abstract}

Brown spot of pear (BSP), caused by the fungus Stemphylium vesicarium (Wallr.) E. G. Simmons, has been reported in the most important pear-growing areas of Europe, which are located in Italy, Spain, The Netherlands, Belgium, and Portugal (Blancard et al. 1989; Heijne and Van Mourik 2001; Llorente and Montesinos 2006; Ponti et al. 1982; Vilardell 1988). The symptoms of BSP include necrotic lesions on fruit, leaves, petioles, and twigs. High disease incidence can provoke premature defoliation in trees and cause fruit drop. The severity of BSP varies from year to year and with climatic conditions, and yield losses may range between 1 and $10 \%$ of the total production despite the control measures applied (Llorente and Montesinos 2006; Llorente et al. 2012). BSP control is mainly based on the use of fungicides applied at fixed schedules or according to the BSP forecasting system (BSPcast) (Llorente et al. 2000; Montesinos et al. 1995).

The BSPcast model predicts infection risk and quantifies the effect of daily wetness duration and temperature during wetness periods on BSP disease (Llorente and Montesinos 2006; Llorente et al. 2000; Montesinos et al. 1995). The use of BSPcast reduces significantly the number of fungicide treatments compared with standard fungicide schedules (Llorente et al. 2000). To increase the efficacy in disease control, different sanitation methods have been proposed for reducing inoculum production on orchard ground, such as by leaf litter removal during winter and biological control applications based on Trichoderma spp. (Llorente et al. 2008, 2010).

However, the use of chemical control with fungicides is currently the main strategy for managing BSP, which still faces several problems for a sustainable use. An accurate timing application of fungicides before or at the beginning of the infection process is very important because $S$. vesicarium produces SV toxins during its growth. If fungicides are not applied during the start of the infection process, toxins have already been released, and then necrosis will appear on the leaves or fruit and control will be not effective (Llorente and Montesinos 2006; Singh et al. 1999, 2000). Unfortunately, no curative fungicides are available for controlling BSP (Llorente

Corresponding author: I. Llorente; E-mail: isidre.llorente@udg.edu

Accepted for publication 12 June 2015.

http://dx.doi.org/10.1094/PDIS-03-15-0250-RE

(C) 2015 The American Phytopathological Society et al. 2012). Strains of $S$. vesicarium resistant to strobilurins and dicarboximide fungicides have been detected (Alberoni et al. 2005, 2010). Additionally, the high frequency of fungicide sprays needed to maintain disease levels below tolerance thresholds may result in high residue levels in fruit and strong environmental impacts on orchards. Thus, there is a need for new fungicides for BSP control.

Synthetic antimicrobial peptides have attracted attention as novel fungicides (Keymanesh et al. 2009; López-García et al. 2002; Montesinos 2007; Montesinos et al. 2012; Montesinos and Bardaji 2008). Several peptides of the CECMEL11 library (Ferre et al. 2006), comprising cecropin A-melittin hybrid undecapeptides, were found to be active in preventing postharvest infections in apple caused by the blue-mold fungus Penicillium expansum (Badosa et al. 2009). Interestingly, one of these peptides, BP15, showed fungicidal effects against $S$. vesicarium with postinfection activity in detached pear leaves (Puig et al. 2014). However, the performance of BP15 has not been tested under field conditions in whole plants or orchards.

The goal of the present study was to evaluate the efficacy of BP15 for controlling BSP under orchard conditions. The experiments were performed in potted pear plants and in pear trees in experimental orchards. The treatment applications were timed according to BSPcast model schedules.

\section{Materials and Methods}

Peptide synthesis. The peptide BP15 (KKLFKKILKVL-NH ${ }_{2}$ ) was obtained at $>90 \%$ purity from LIPPSO (University of Girona, Spain). It was synthesized using solid-phase methodology with 9-fluorenylmethoxycarbonyl-type chemistry, tert-butyloxycarbonyl side-chain protection for Lys and Trp, and tert-butyl for Tyr, as previously described (Badosa et al. 2009; Ferre et al. 2006).

Weather parameters measurement. Environmental parameters were monitored with a CR10x datalogger (Campbell Scientific Ltd.) connected to temperature and relative humidity (RH) (model HMP35AC), wetness (model 236), and rainfall (model ARG100) sensors. Automatic weather stations were placed on the experimental orchards. Temperature and RH were measured every $10 \mathrm{~min}$, and leaf wetness duration and rainfall were measured every $20 \mathrm{~s}$. Mean temperature, mean RH, total duration of wetness, and total rainfall were recorded every hour.

Potted plant trials in pear orchards. Trials were performed in two locations during July and September 2011 in Catalonia (northeastern of Spain). Orchard A, located in Girona (41 ${ }^{\circ} 57^{\prime} 37.16^{\prime \prime} \mathrm{N}$, 
$2^{\circ} 49^{\prime} 51.84^{\prime \prime} \mathrm{E}$ ), comprised 0.5 ha of different pear cultivars; orchard $\mathrm{B}$, located in Campllong (Girona) (41 $\left.{ }^{\circ} 54^{\prime} 27.2^{\prime \prime} \mathrm{N} \mathrm{2}{ }^{\circ} 49^{\prime} 12.0^{\prime \prime} \mathrm{E}\right)$, comprised 2 ha of 'Passe Crassane' pear. The disease incidence of BSP on leaves in the preceding year in orchard A was very low $(<5 \%)$ whereas, in orchard B, it was high $(80 \%)$. According to this, the amount of natural inoculum during the trials was expected to be low on orchard A and high on orchard B.

Self-rooted, potted 'Conference' pear plants grown in the greenhouse were pruned, leaving only one shoot. When plants reached a height of 0.75 to $1 \mathrm{~m}$, they were used for the experiments. These plants were transported to orchards A and B for exposure to natural conditions. Plants used in the experiments performed in orchard A were artificially inoculated with $S$. vesicarium strain EPS26 due to the low level of natural inoculum in this orchard, whereas plants used in the trials performed in orchard B were exposed to natural inoculum in the orchard.

To obtain inoculum for the experiments in orchard A, S. vesicarium EPS26 was grown on tomato agar plates $(800 \mathrm{ml}$ of distilled water, $10 \mathrm{~g}$ of tomato concentrated juice, $2.3 \mathrm{~g}$ of $\mathrm{CaCO}_{3}$, and $12.8 \mathrm{~g}$ of agar) for 7 to 10 days at $22.5^{\circ} \mathrm{C}$ with a 16 -h light photoperiod in a growth cabinet (I-30BLL Percival Plant Biology Chamber; Percival Scientific Inc.). Then, conidia were collected from the agar surface, transferred to distilled water, and filtered. The concentration of the suspension was determined by counting the conidia in five drops (10 $\mu$ l each) under a microscope. Finally, the conidial concentration was adjusted to $10^{3}$ conidia $/ \mathrm{ml}$. Potted pear plants were inoculated with the conidia suspension until runoff by using an airbrush after having been placed in the orchard.

The experimental factors consisted of treatment with peptide BP15 and a nontreated control. BP15 $(20 \mathrm{ml})$ at $100 \mu \mathrm{M}(135.7 \mathrm{mg} / \mathrm{liter})$ was applied per plant. Three plants were used per treatment and control. Sprays were scheduled according to the infection risk level determined by the BSPcast model (Llorente et al. 2000; Montesinos et al. 1995). The threshold for BP15 application was the cumulative risk $(C R) \geq 0.4$. Different sets of six plants were transported to each experimental orchard and randomly distributed among the pear trees in July and September. Different code numbers were assigned to trials to facilitate easy identification in this report (Table 1).

With the purpose to test the efficacy of BP15 applied at different times, sprays were done on the same day that the $\mathrm{CR} \geq 0.4$ threshold was reached in trials A1, A3, A4, B1, and B3; or after $24 \mathrm{~h}$ (A2, A5, $\mathrm{B} 2$, and B4) or $48 \mathrm{~h}$ (A6 and B5).

In trials performed in orchard B, corresponding to pear plants exposed to natural inoculum, plants were left in the orchard for an initial period of 5 days to ensure natural inoculation with the pathogen before the treatments started.

In each trial, the peptide BP15 was applied to the corresponding potted plants using an airbrush. After the treatment, the plants remained

Table 1. Characteristics of trials performed for evaluation of peptide BP15 efficacy in controlling brown spot of pear on potted pear plants incubated under natural conditions

\begin{tabular}{lccc}
\hline Code & Orchard $^{\text {a }}$ & Input date $^{\mathbf{b}}$ & Treatment date $^{\mathbf{c}}$ \\
\hline A1 & A & $06 / 07 / 2011$ & $13 / 07 / 2011$ \\
A2 & A & $06 / 07 / 2011$ & $14 / 07 / 2011$ \\
A3 & A & $14 / 07 / 2011$ & $20 / 07 / 2011$ \\
A4 & A & $20 / 07 / 2011$ & $27 / 07 / 2011$ \\
A5 & A & $08 / 09 / 2011$ & $12 / 09 / 2011$ \\
A6 & A & $08 / 09 / 2011$ & $13 / 09 / 2011$ \\
B1 & B & $06 / 07 / 2011$ & $13 / 07 / 2011$ \\
B2 & B & $06 / 07 / 2011$ & $14 / 07 / 2011$ \\
B3 & B & $07 / 09 / 2011$ & $12 / 09 / 2011$ \\
B4 & B & $07 / 09 / 2011$ & $13 / 09 / 2011$ \\
B5 & B & $07 / 09 / 2011$ & $14 / 09 / 2011$ \\
\hline
\end{tabular}

\footnotetext{
a Orchard A was located in Girona and orchard B in Campllong.

${ }^{b}$ Date when potted plants where placed on the orchard.

c Date of BP15 applications. Plants remained under natural conditions for $24 \mathrm{~h}$ after the treatment.
}

for $24 \mathrm{~h}$ in the orchard to be exposed to natural conditions, aimed to allow the peptide and $S$. vesicarium to interact under field conditions. Then, plants were transported to the laboratory and incubated for 7 days in a controlled-environment chamber for the expression of symptoms (16-h light photoperiod, $\left.22.5^{\circ} \mathrm{C}, 70 \% \mathrm{RH}\right)$. Disease severity was recorded by visually determining the number of lesions per pear leaf on the five youngest leaves in each treated and control plant. Disease severity was assessed on the day when the treatment was applied and 7 days after, and only new lesions were considered. In total, 11 sets of plants were used.

Data analysis. Data were analyzed using $\mathrm{R}$ statistical software ( $\mathrm{R}$ Core Team 2014). When the disease severity observed in nontreated control plants was lower than one lesion per leaf, this trial was excluded from the analysis. Accordingly, the data finally analyzed corresponded to four of six plant sets from orchard A (trials A3, A4, A5, and A6) and three of five from orchard B (B3, B4, and B5). The datasets were tested for equality of variances (Bartlett) and normality (Shapiro-Wilk). The effect of peptide on the disease severity was determined by analysis of variance using mixed models with the lme 4 and lmerTest packages. The treatment was considered as a fixed factor, the plants as a random factor, and the data of each leaf nested within plants. Mean comparisons were performed with Tukey's contrast test. Efficacy of treatments was calculated as $\mathrm{E}=\left[1-\left(y_{t} / y_{\mathrm{nt}}\right)\right] \times 100$, where $\mathrm{E}$ is the efficacy in disease control, $\mathrm{y}_{\mathrm{nt}}$ is the disease severity in the nontreated control, and $\mathrm{y}_{\mathrm{t}}$ is the disease severity in treated plants. The effect of trial on the efficacy in disease control of BP15 was evaluated using one-way analysis of variance. Because no significant differences were observed between trials $(P=0.9183)$, pooled data were analyzed. The one-way analysis of variance was used to determine the effect of application time $(0,24$, or $48 \mathrm{~h})$ after BSPcast threshold was achieved on the efficacy in disease control. The datasets were tested for equality of variances (Bartlett) and normality (Shapiro-Wilk).

Climatic conditions during the trials. The variations of temperature, rainfall, and wetness duration recorded during the trials are presented in Figure 1. The monthly average daily mean temperatures during July and September were 20.1 and $22.5^{\circ} \mathrm{C}$, respectively, in orchard A and 22.5 and $23.5^{\circ} \mathrm{C}$, respectively, in orchard B (Fig. 1). Rainfall occurred only from the middle to the end of July, with an intense rainfall of $114 \mathrm{~mm}$ in orchard A. No rainfall events were observed in September in orchard B. The wetness period varied during July, when $26 \%$ of days in orchard A and $10 \%$ of days in orchard B had a wetness duration longer than $12 \mathrm{~h}$. In September, 50\% of days in orchard A and $67 \%$ of days in orchard B experienced long wetness periods.

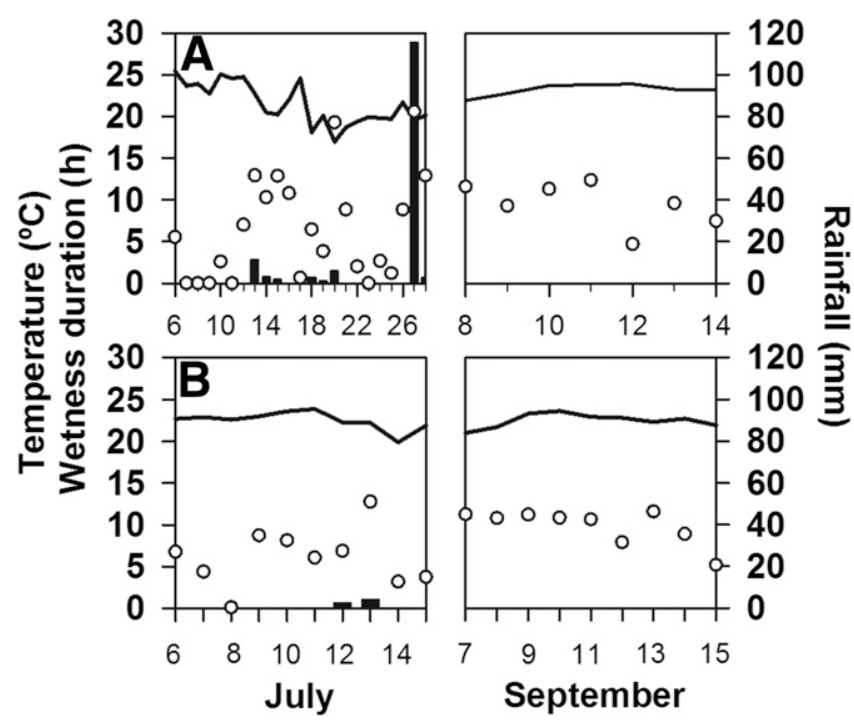

Fig. 1. Variation of mean temperature (solid line), daily wetness duration (circles), and rainfall (bars) during the trial periods in 2011. Upper panels correspond to orchard A and lower panels to orchard B. Trials were performed using potted plants incubated under natural conditions. 
Tree trials in pear orchards. Four field trials were conducted in orchard B (Campllong, 41 ${ }^{\circ} 54^{\prime} 27.2^{\prime \prime}$ N 2 $2^{\circ} 49^{\prime} 12.0^{\prime \prime} \mathrm{E}$ ) in Passe Crassane pear during the growing seasons of 2012 (trials I and II) and 2013 (trials III and IV). This orchard was chosen because the incidence of BSP in the preceding years had been very high (70\% on fruit and $80 \%$ on leaves).

Previously, a sanitation method of control was applied in part of the orchard to obtain two levels of $S$. vesicarium inoculum in the same orchard (Llorente et al. 2010). This sanitation method involved covering part of the orchard ground $\left(300 \mathrm{~m}^{2}\right)$ with a plastic foil to reduce the production and release of inoculum by leaf litter. In the rest of the orchard area (approximately 1,200 $\mathrm{m}^{2}$ ), no sanitation method was applied, and the orchard remained unaltered.

Trials I and III (high inoculum pressure) were conducted in an area of the orchard where no sanitation method was applied, and trials II and IV (medium inoculum pressure) were placed in the area with plastic foil covering the ground. In all trials, a complete randomized block design with three blocks was used. Each block consisted of 12 trees (trials II and IV) or 18 trees (trials I and III) of which 4 or 6, respectively, were used. In each of the trees used, six shoots (two per treatment), with at least 10 leaves, located in the middle of canopy, were labeled at the beginning of the season, in May. The trials started in May and ended in September.

The treatments evaluated were the peptide BP15 at $100 \mu \mathrm{M}$ ( $135.7 \mathrm{mg} /$ liter), thiram (2,000 $\mathrm{mg}$ a.i./liter) as a reference fungicide, and the nontreated control. Peptide and fungicide applications were scheduled according to the BSPcast model. Sprays were applied when the daily infection risk $(\mathrm{R}) \geq 0.2$ or the cumulative infection risk was $\mathrm{CR} \geq 0.4$ (Llorente et al. 2011). Peptide or thiram solutions were applied on labeled shoots until runoff (16 ml per shoot) using a commercial portable sprayer. It was assumed that the fungicide thiram provided 7-day protection, except when rainfall was higher than $20 \mathrm{~mm}$. For peptide BP15, 1-day protection was considered, according to a previous report (Puig et al. 2014).

Disease severity was assessed on all leaves of each labeled shoot by counting the number of lesions per leaf every 15 to 20 days and at the end of the trials. Mean disease incidence and severity were calculated per shoot.

Data analysis. Data were analyzed using $\mathrm{R}$ statistical software ( $\mathrm{R}$ Core Team 2014). The data sets were tested for equality of variances (Bartlett) and normality (Shapiro-Wilk).

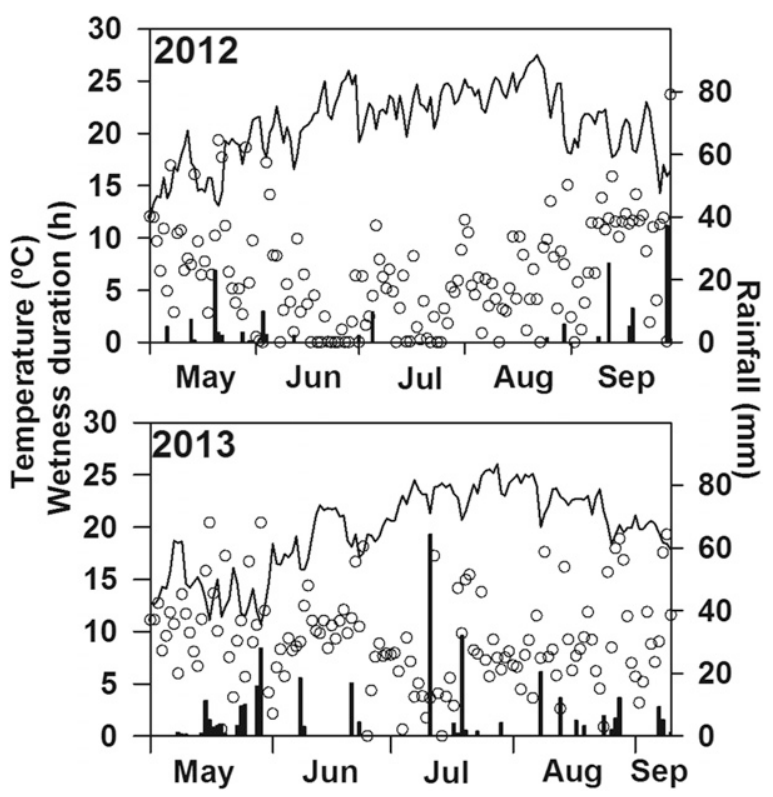

Fig. 2. Variation of mean temperature (solid line), daily wetness duration (circles), and rainfall (bars) during field trials performed in 2012 and in 2013 in the experimental pear orchard Campllong.
The effect of treatments on disease severity during the whole epidemic was determined with repeated-measures analysis of variance using mixed models with restricted maximum likelihood comparisons (RMEL). The analysis was performed with Proc GLM using the SAS 9.2 software program (SAS Institute Inc.). The variancecovariance matrix structure was compared according to different models, and compound symmetry structure was chosen because it showed the lowest AIC (Akaike Information Criterion) statistic. Comparison of means was performed with Tukey's contrast test.

The effect of peptide and thiram fungicide treatments on disease severity at the end of the trials was determined by analysis of variance using mixed models obtained with the $1 \mathrm{mr}$ function and RMEL with R statistical software (R Core Team 2014). One fixed factor (treatment), random blocks, and subsampling within the experimental unit were considered because data from the shoots and trees were nested within blocks. Comparisons of the means were performed with Tukey's contrast test.

Climatic conditions during the trials. During the years 2012 and 2013, July and August were characterized as the warmest months (Fig. 2). The average daily mean temperature for 2012 (trials I and II) was $20.9^{\circ} \mathrm{C}$, with a minimum temperature of $11.8^{\circ} \mathrm{C}$ and a maximum temperature of $27.5^{\circ} \mathrm{C}$. The range of temperatures in 2013 (trials III and IV) was from 10.7 to $26^{\circ} \mathrm{C}$, with an average daily mean temperature of $19.6^{\circ} \mathrm{C}$. The rainfall in 2013 was double that of 2012, with an accumulated rainfall of $341 \mathrm{~mm}$ by the end of the study. In 2012, the period from June to August was dry, with few rain events. Days with longer wetness duration periods in both years were concentrated in May and September; additionally, in 2013, some days of long wetness duration occurred in July and August. The variation of meteorological parameters in 2012 and 2013 showed a relationship between days with rain and long leaf wetness periods.

\section{Results}

Potted plant trials in pear orchards. The variation of disease risk forecasted by BSPcast for each trial is shown in Figure 3. Data from trials A1, A2, B1, and B2 were not used in the analysis because the disease severity in the nontreated controls was lower than one lesion per leaf. Also, in these trials, the number of days with infection risk $\mathrm{CR} \geq 0.4$ was very low. In the remaining useful trials, the BSP risk predicted for the days before peptide application was high. In general, the disease severity observed in nontreated plants artificially
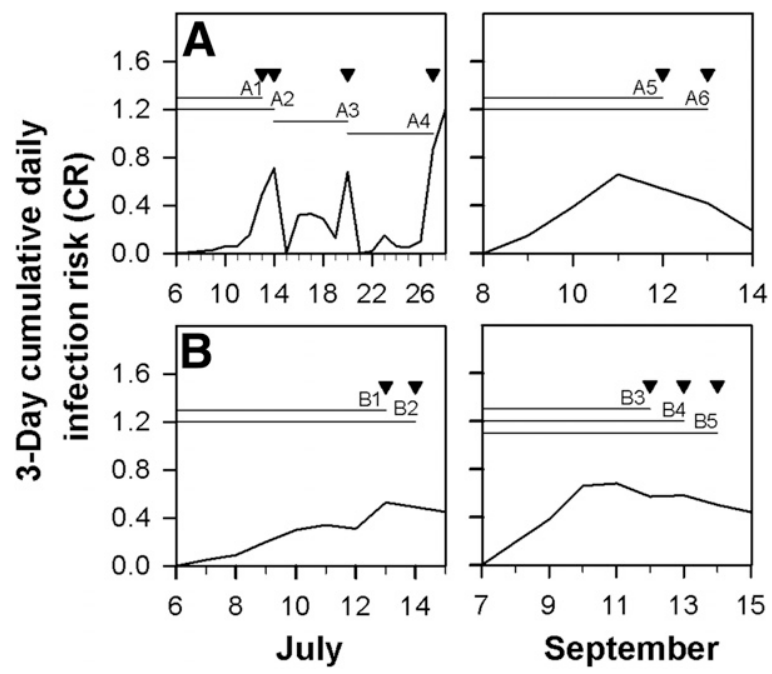

Fig. 3. Variation of 3-day cumulative daily infection risk (CR) in trials performed using potted plants incubated in pear orchards during July and September 2011. Upper panels show trials $A 1$ to $A 6$ performed in orchard $A$ and lower panels show trials $\mathrm{B} 1$ to $\mathrm{B} 5$ performed in orchard $\mathrm{B}$. Horizontal lines indicate the period of time when the plants were incubated in the orchard for each trial until treatments with BP15 $(\boldsymbol{\nabla})$ were done. Treatments were applied on the same day that the $C R \geq 0.4$ threshold was reached in trials $A 1, A 3, A 4, B 1$, and $B 3$; after $24 \mathrm{~h}$ in trials $A 2, A 5$, $\mathrm{B} 2$, and $\mathrm{B} 4$; and after $48 \mathrm{~h}$ in trials $\mathrm{A} 6$ and $\mathrm{B} 5$. 
inoculated (orchard A) was higher (4.1 to 27.6 lesions/leaf) than that observed in the plants exposed to natural inoculum (orchard B) (2.6 to 4.1 lesions/leaf; Fig. 4). The effect of BP15 treatments in reducing disease severity was significant in five of seven trials (A4, A6, B3, B4, and B5) compared with the nontreated control (Fig. 4). The efficacy for disease control of BP15 in orchard A was $42.5 \%$ in trial A6 and $48.1 \%$ in trial A4 and, in orchard B, was 59.5, 59.7, and 53.3\% in trials B3, B4, and B5, respectively.

No significant differences $(P=0.938)$ were observed in the efficacy of BP15 for BSP control whatever the time application after the $\mathrm{CR}$ threshold was reached $(0,24$, or $48 \mathrm{~h})$, with a mean efficacy of $48.5,47.9$, and $54.4 \%$ respectively.

Tree trials in pear orchards. In trials performed during 2012 and 2013, the treatments were sprayed according to the daily infection risk index $(R \geq 0.2)$ or the cumulative infection risk index $(C R \geq$ 0.4). The first high value of $R$ and $C R$ occurred in May (Fig. 5) in both years, after days with rain. In 2012, the R and CR values were high in May, August, and September. In the period of study, $R$ values reached the action threshold level of 0.2 in 27 days and the $C R \geq 0.4$ in 42 days (until 24 September); in total, 19 sprays of BP15 and 14 of thiram were applied (Fig. 5). In 2013, the number of days that $\mathrm{R} \geq$ 0.2 was 27 and the number of days with $C R \geq 0.4$ was 60 (until 4
September). However, the number of sprays in the 5-month trials was 15 for BP15 and 12 for thiram (Fig. 5).

The progression of disease severity in shoots treated with the peptide BP15 or thiram was compared with that in nontreated controls for the four trials over 2 years (Fig. 5). In all cases, the epidemic started in May after periods with high R and CR values. In 2012, the rate of disease progress was high at the beginning and at the end of the epidemic (May and September). During July and August, the disease did not progress due to the lack of rain and short periods of wetting (Fig. 4). In contrast, in 2013, the epidemic increased during the entire period, especially after July, and the R and CR indexes showed high values during all months due to the rainfall events, including those that occurred in July and August. In all trials, the increases in disease severity coincided with periods with high values of $\mathrm{R}$ and $\mathrm{CR}$.

The final disease severity in shoots treated with BP15 was significantly lower than in the nontreated shoots in three of four trials (I, III, and IV) (Table 2). In these trials (I, III, and IV), the mean disease severity observed in shoots treated with BP15 was 8.5, 8.2, and 6.6 lesions/leaf, respectively, whereas 13.4, 13.8, and 10.6 lesions/leaf were observed in the nontreated shoots. The mean disease severity observed when BP15 or thiram were applied was
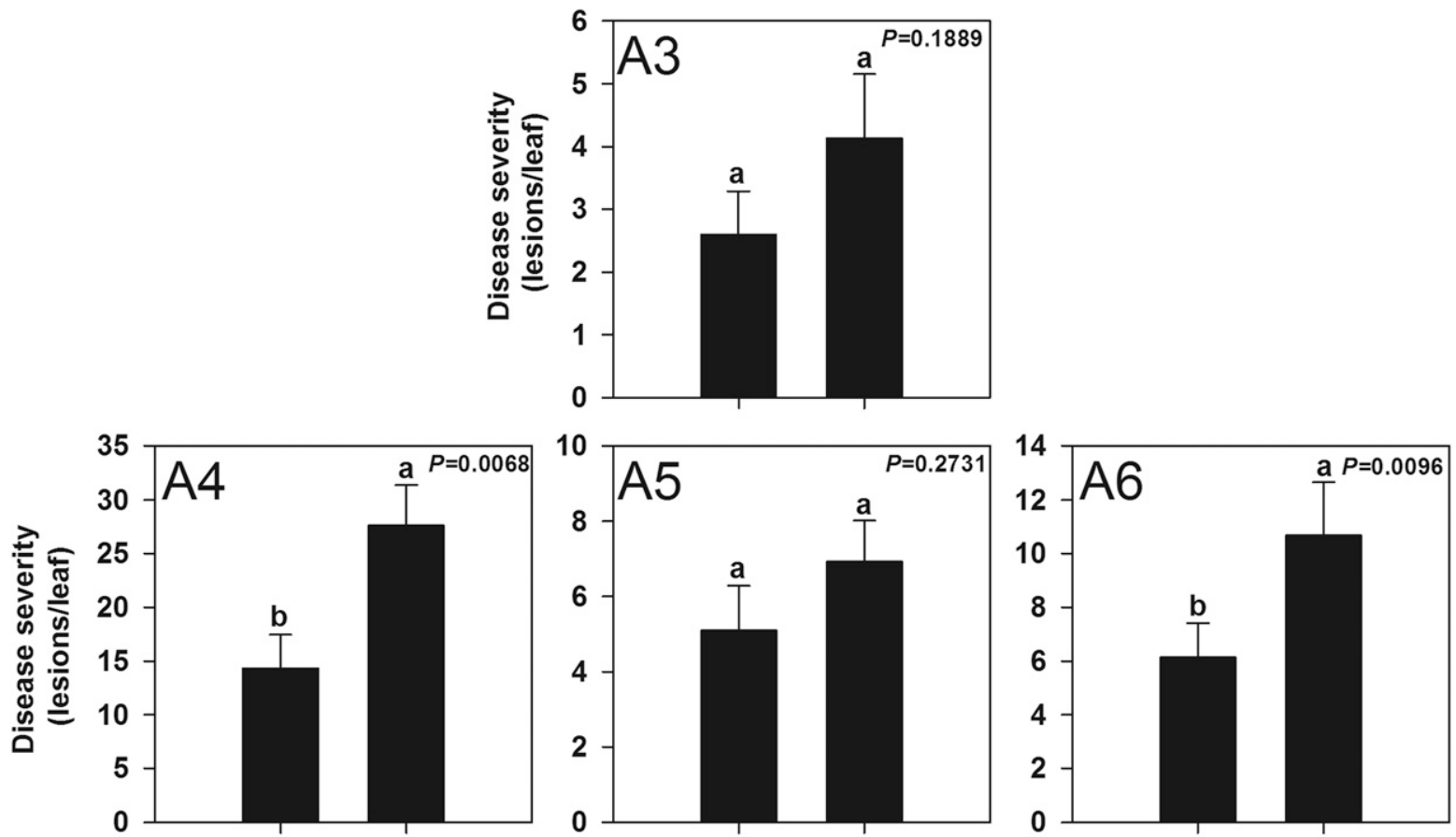

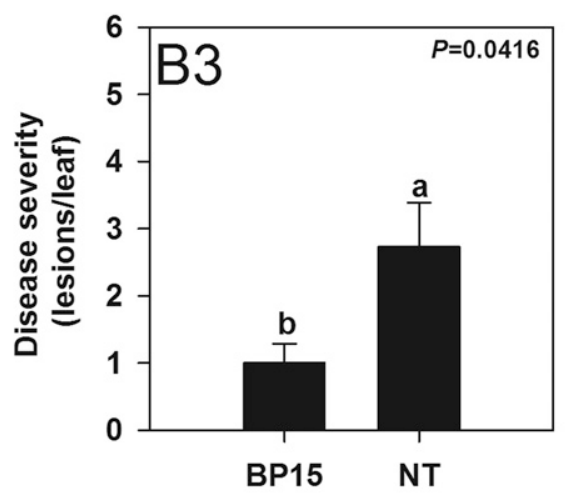

Treatment
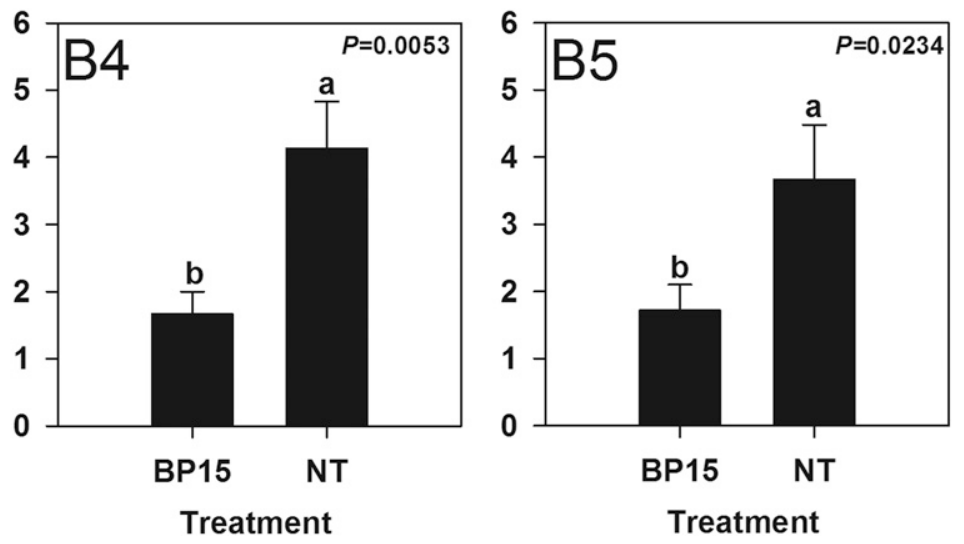

Fig. 4. Effect of peptide BP15 treatments and the nontreated control (NT) on disease severity (lesions/leaf) in seven trials performed using potted plants in pear orchards. Panels show trials $A 3$ to $A 6$ performed in orchard $A$ and trials $B 3$ to $B 5$ performed in orchard $B$. Treatments were applied on the same day that the $C R \geq 0.4$ threshold was reached in trials $\mathrm{A} 3, \mathrm{~A} 4$, and B3; after $24 \mathrm{~h}$ in trials $\mathrm{A} 5$ and B4; and after $48 \mathrm{~h}$ in trials A6 and B5. Values of each bar are the mean of three replicates, with five leaves per replicate. The standard error of the mean is also indicated. Values followed by the same letter are not significantly different according to Tukey's test $(P \leq 0.05)$. $P$ values are presented. 
similar in two trials (III and IV), with 8.2 and 6.6 lesions/leaf, respectively, in shoots treated with BP15 and 8.1 and 6.1 lesions/leaf, respectively, in shoots treated with thiram. In contrast, the disease severity differed significantly between shoots treated with BP15 and thiram in trials I and II, with an average of 8.5 and 5.5 lesions/leaf, respectively, for BP15 and 5.6 and 2.1 lesions/leaf, respectively, for thiram. In all trials, the disease severity was significantly lower in shoots treated with thiram in comparison with the nontreated control. The efficacy of disease control observed in trials I, II, III, and IV was $37.1,9.2,40.4$, and $37.1 \%$, respectively, with BP15 and 58.1, 65.6, 40.9, and 42.2\%, respectively, with thiram.

Similar results were obtained upon analyzing the whole epidemic by means of a repeated-measures analysis (Table 3 ). In trials I, III, and IV, the disease severity was reduced significantly by 20.8 , 31.5 , and $33.3 \%$, respectively, on shoots treated with BP15 in comparison with the nontreated shoots. No significant differences in disease severity were observed between leaves treated with BP15 and with thiram in trials II, III, and IV. In all trials, thiram reduced significantly the disease severity by $45.3,49.2,45.9$, and $53.4 \%$ compared with the nontreated control.

\section{Discussion}

In recent years, several synthetic antimicrobial peptides have been reported with antifungal activity. For example, the peptides BP76,
BP21, and BP22 from the CECMELL11 library were effective in controlling blue-mold rot caused by $P$. expansum on apple fruit; PAF19, PAF26, and $\mathrm{LfcinB}_{4-9}$ inhibited $P$. digitatum and $P$. italicum on orange fruit; C14-KLLK avoided the development of Botrytis cinerea on cucumber leaves and fruit; and AFP controlled Magnaporthe grisea infection in rice (Badosa et al. 2009; López-García et al. 2003; Makovitzki et al. 2007; Vila et al. 2001).

Table 2. Effect of different treatments on disease severity (lesions/leaf) in four field trials performed in Campllong experimental orchard in 2012 (trials I and II) and 2013 (trials III and IV) ${ }^{\mathrm{a}}$

\begin{tabular}{|c|c|c|c|c|}
\hline \multirow[b]{3}{*}{ Treatment contrasts } & \multicolumn{2}{|c|}{2012} & \multicolumn{2}{|c|}{2013} \\
\hline & Trial I & Trial II & Trial III & Trial IV \\
\hline & $P>z$ & $P>z$ & $P>z$ & $P>z$ \\
\hline BP15 vs. nontreated & $<0.001 * * *$ & $0.8111 \mathrm{~ns}$ & $<0.001 * * *$ & $0.0055 * *$ \\
\hline BP15 vs. thiram & $0.0138 *$ & $0.0127 *$ & $0.9960 \mathrm{~ns}$ & $0.9040 \mathrm{~ns}$ \\
\hline Thiram vs. nontreated & $<0.001 * * *$ & $0.0021 * *$ & $<0.001 * * *$ & $0.0012 * *$ \\
\hline
\end{tabular}

${ }^{\text {a }}$ Data correspond to linear contrasts for disease severity at the end of the trials. Asterisks *, **, and $* * *$ indicate significant at $0.05,0.01$, and $<0.001$ probability levels, respectively; ns $=$ not significant at $P \leq 0.05$. Adjusted $P$ values according to Tukey's contrast test.
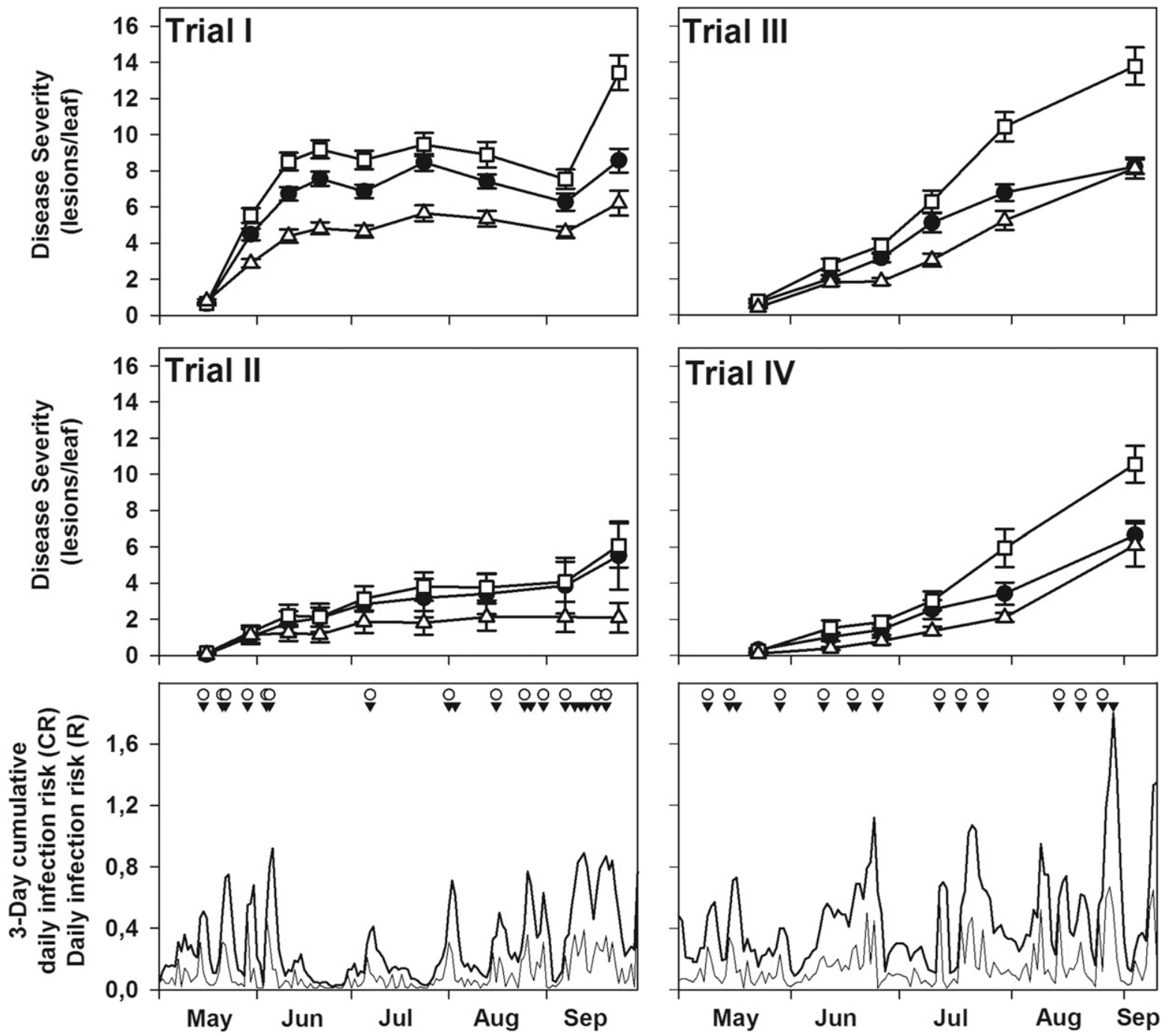

Fig. 5. Brown spot disease severity progress curves on leaves for nontreated control $(\square)$, leaves treated with the peptide BP15 $(\square)$, and leaves treated with thiram $(\Delta)$ at $R_{m} \geq 0.2$ or $C R \geq 0.4$, in relation to the daily infection risk (R) (fine line) and the variation of 3-day cumulative daily infection risk (CR) (bold line). Field trials were performed in the experimental pear orchard Campllong in 2012 (left) and 2013 (right). Dates of treatments with BP15 $(\boldsymbol{\nabla})$ and thiram $(\bigcirc)$ are indicated. Values of disease severity are the mean of three replicates, with four shoots per replicate in trials I and III and two shoots per replicate in trials II and IV. Bars represent the standard error of the mean. 
In one of our previous studies, it was demonstrated that BP15 stopped the growth of $S$. vesicarium under in vitro and ex vivo conditions (Puig et al. 2014). In the present work, the efficacy of BP15 in the control of BSP was evaluated under field conditions.

The results presented here are most likely the first evidence of the effectiveness of a synthetic peptide in the control of a plant disease under field conditions. In potted plants, BP15 significantly reduced the intensity of BSP, with a mean efficacy ranging from $45.3 \%$ (orchard A) to $57.5 \%$ (orchard B). The levels of disease in nontreated controls were higher in orchard A than in orchard B but no significant differences in the efficacy of disease control were observed among trials. BP15 treatments were not always performed on the day the BSPcast action threshold was reached. Consequently, in some cases, the potted plants remained unprotected for 24 or $48 \mathrm{~h}$ after the $S$. vesicarium infection had occurred. However, BP15 treatments showed a high efficacy in disease control whatever the time of application after the risk advice. Similar results were obtained in previous research on detached leaves treated with BP15 from 6 to $24 \mathrm{~h}$ after the infections started. These results can be explained by the postinfection activity of BP15, which binds directly to the hyphae of $S$. vesicarium; thus, fungal growth is rapidly inhibited (Puig et al. 2014).

To evaluate the efficacy of BP15 on BSP control in pear trees, the peptide was applied over 2 years on shoots in trees with different levels of disease, as measured in the nontreated controls (from 6.1 to 13.8 lesions/leaf). The results obtained upon treatment of tree shoots were consistent in most of the trials. In three of four trials, the disease severity on leaves, assessed at the end of the trials or during the whole epidemic, was reduced when shoots were treated with the peptide in comparison with the nontreated control. These results state that BP15 is an effective fungicide against $S$. vesicarium infections applied according to the BSPcast model under different climatic conditions and different disease levels. The efficacy of disease control on leaves using fungicides such as thiram alone or complemented with sanitation measures has been described to be between 30 and $60 \%$ (Antoniacci et al. 2006; Llorente et al. 2010). Interestingly, these values are in the same range of efficacy observed in three of four trials presented herein using BP15 (38.2\%). The efficacy of disease control using thiram was higher $(47.1 \%)$. Unfortunately, disease control was incomplete using either thiram or BP15, probably related to the production of two host-specific toxins (SV toxins I and II) by $S$. vesicarium during the infection process before the fungicides have controlled the fungal growth (Singh et al. 1999, 2000).

Treatment with BP15 could have additional benefits in comparison with thiram or other fungicides: (i) the peptide is composed of proteinogenous amino acids and already degradable by proteases; thus, it is not expected to produce residues on fruit; (ii) the mechanism of action is by membrane damage, and then a low probability of resistance in the target pathogen is also expected (Güell et al. 2011; Puig et al. 2014). Antifungal peptides are normally degraded within a few minutes when exposed to the natural environment due to the activity of proteases from leaves and fruit (Badosa et al. 2009; Ferre et al. 2006; Güell et al. 2011; Keymanesh et al. 2009; Montesinos 2007; Montesinos et al. 2012). The high postinfection

Table 3. Effect of applications of BP15 and thiram for controlling brown spot of pear during the whole epidemics ${ }^{\mathrm{a}}$

\begin{tabular}{|c|c|c|c|c|}
\hline \multirow[b]{3}{*}{ Treatment contrasts } & \multicolumn{2}{|c|}{2012} & \multicolumn{2}{|c|}{2013} \\
\hline & Trial I & Trial II & Trial III & Trial IV \\
\hline & $P>z$ & $P>z$ & $P>z$ & $P>z$ \\
\hline BP15 vs. nontreated & $0.0488 *$ & $0.7806 \mathrm{~ns}$ & $<0.001 * * *$ & $0.0019 * * *$ \\
\hline BP15 vs. thiram & $0.0147 *$ & $0.0611 \mathrm{~ns}$ & $0.1225 \mathrm{~ns}$ & $0.0979 \mathrm{~ns}$ \\
\hline Thiram vs. nontreated & $<0.001 * * *$ & $0.0098 * * *$ & $<0.001 * * *$ & $<0.001 * * *$ \\
\hline
\end{tabular}

a Field trials were performed in Campllong experimental orchard during 2012 (trial I and II) and 2013 (trial III and IV). Data corresponds to linear contrasts for disease severity by repeated measures. Asterisks *, **, and *** indicate significant at $0.05,0.01$, and $<0.001$ probability levels, respectively; ns $=$ not significant at $P \leq 0.05$. Adjusted $P$ values according to Tukey's contrast test. activity of BP15 against $S$. vesicarium indicates that the persistence of the peptide in the leaf environment is sufficient to be effective. Additionally, BP15 does not exhibit cytotoxicity in erythrocytes or on plant tissues at effective antifungal concentrations (Badosa et al. 2009; Ferre et al. 2006; Puig et al. 2014). In addition, toxicity in animals is very low according to oral ingestion tests in mice, with a median lethal dose in the range of 1,000 to $2,000 \mathrm{mg} / \mathrm{kg}$ of body weight (Montesinos et al. 2012).

The results obtained in field experiments over 2 years provide evidence that BP15 is a good candidate for developing new pesticides for BSP management as an alternative or complement to conventional fungicide treatments scheduled with the BSPcast warning system. The postinfection activity of BP15 against $S$. vesicarium offers new possibilities in an integrated pest management strategy to control BSP. In pear orchards with low levels of disease, the use of BP15 may be enough to control BSP applied according to the risk predicted by the BSPcast model. In orchards with higher disease levels, BP15 should be combined with conventional fungicides. Today, weather forecasts are accurate enough to apply fungicides preventively, a few hours before the infections really begin. Then, once the BSPcast model confirms that climatic conditions are favorable to trigger the infections, the BP15 should be applied to inhibit the growth of conidia that remain viable. This strategy can increase the efficacy of BSP control without increasing the fungicide residue levels on fruit.

One of the main limitations for commercial use of peptides as pesticides is the high economic costs of production. Additional efforts to obtain and optimize formulation are necessary to develop antimicrobial peptides for agricultural uses. Research to better understand the mechanisms of action and to optimize mass-production systems for field testing against BSP and other fungal diseases of crops is ongoing.

\section{Acknowledgments}

This research was supported, in part, by grants from the Ministerio de Educación y Ciencia (AGL2009-09829/AGR) of Spain. M. Puig was the recipient of a predoctoral fellowship from Universitat de Girona (BR10-17). We thank E. Agustí and J. Pereda for their helpful assistance in field work.

\section{Literature Cited}

Alberoni, G., Cavallini, D., Collina, M., and Brunelli, A. 2010. Characterisation of the first Stemphylium vesicarium isolates resistant to strobilurins in Italian pear orchards. Eur. J. Plant Pathol. 126:453-457.

Alberoni, G., Collina, M., Pancaldi, D., and Brunelli, A. 2005. Resistance to dicarboximide fungicides in Stemphylium vesicarium of Italian pear orchards. Eur. J. Plant Pathol. 113:211-219.

Antoniacci, L., Bugiani, R., and Rossi, R. 2006. Control of brown spot of pear in organic pear orchard. IOBC/WPRS Bull. 29:117-122.

Badosa, E., Ferre, R., Francés, J., Bardají, E., and Feliu, L. 2009. Sporicidal activity of synthetic antifungal undecapeptides and control of Penicillium rot of apples. Appl. Environ. Microbiol. 75:5563-5569.

Blancard, D., Allard, E., and Brest, P. 1989. La stemphyliose du poirier ou "macules brunes". Phytoma 406:35-37.

Ferre, R., Badosa, E., Feliu, L., Planas, M., Montesinos, E., and Bardají, E. 2006. Inhibition of plant-pathogenic bacteria by short synthetic cecropin A-melittin hybrid peptides. Appl. Environ. Microbiol. 72:3302-3308.

Güell, I., Cabrefiga, J., Badosa, E., Ferre, R., Talleda, M., Bardají, E., Planas, M., Feliu, L., and Montesinos, E. 2011. Improvement of the efficacy of linear undecapeptides against plant-pathogenic bacteria by incorporation of D-amino acids. Appl. Environ. Microbiol. 77:2667-2675.

Heijne, B., and Van Mourik, J. 2001. Zwart-vruchtrot op peer neemt toe. Fruitt. Den Haag 91:18-19.

Keymanesh, K., Soltani, S., and Sardari, S. 2009. Application of antimicrobial peptides in agriculture and food industry. World J. Microbiol. Biotechnol. 25: 933-944.

Llorente, I., and Montesinos, E. 2006. Brown spot of pear: An emerging disease of economic importance in Europe. Plant Dis. 90:1368-1375.

Llorente, I., Moragrega, C., Ruz, L., and Montesinos, E. 2012. An update on control of brown spot of pear. Trees 26:239-245.

Llorente, I., Vilardell, A., Vilardell, P., and Montesinos, E. 2008. Evaluation of new methods in integrated control of brown spot of pear (Stemphylium vesicarium, Teleomorph Pleospora allii). Acta Hortic. 800:825-831.

Llorente, I., Vilardell, A., Vilardell, P., Pattori, E., Bugiani, R., Rossi, V., and Montesinos, E. 2010. Control of brown spot of pear by reducing the overwintering inoculum through sanitation. Eur. J. Plant Pathol. 128 $127-141$ 
Llorente, I., Vilardell, P., Bugiani, R., Gherardi, I., and Montesinos, E. 2000. Evaluation of BSPcast disease warning system in reduced fungicide use programs for management of brown spot of pear. Plant Dis. 84:631-637.

Llorente, I., Vilardell, P., and Montesinos, E. 2011. Evaluation of a revision of the BSPcast decision support system for control of brown spot of pear. Phytopathol. Mediterr. 50:139-149.

López-García, B., Pérez-Payá, E., and Marcos, J. F. 2002. Identification of novel hexapeptides bioactive against phytopathogenic fungi through screening of a synthetic peptide combinatorial library. Appl. Environ. Microbiol. 68:2453-2460.

López-García, B., Veyrat, A., Pérez-Payá, E., González-Candelas, L., and Marcos, J. F. 2003. Comparison of the activity of antifungal hexapeptides and the fungicides thiabendazole and imazalil against postharvest fungal pathogens. Int. J. Food Microbiol. 89:163-170.

Makovitzki, A., Viterbo, A., Brotman, Y., Chet, I., and Shai, Y. 2007. Inhibition of fungal and bacterial plant pathogens in vitro and in planta with ultrashort cationic lipopeptides. Appl. Environ. Microbiol. 73:6629-6636.

Montesinos, E. 2007. Antimicrobial peptides and plant disease control. FEMS Microbiol. Lett. 270:1-11.

Montesinos, E., Badosa, E., Cabrefiga, J., Planas, M., Feliu, L., and Bardají, E. 2012. Antimicrobial peptides for plant disease control. From discovery to application. Pages 235-261 in: Small Wonders: Peptides for Disease Control. K. Rajasekaran, J. W. Cary, J. M. Jaynes, and E. Montesinos, eds. Oxford University Press, Inc., Washington, DC.

Montesinos, E., and Bardají, E. 2008. Synthetic antimicrobial peptides as agricultural pesticides for plant-disease control. Chem. Biodivers. 5:1225-1237.
Montesinos, E., Moragrega, C., Llorente, I., Vilardell, P., Bonaterra, A., Ponti, I., Bugiani, R., and Brunelli, A. 1995. Development and evaluation of an infection model for Stemphylium vesicarium on pear based on temperature and wetness duration. Phytopathology 85:586-592.

Ponti, I., Cavani, P., and Brunelli, A. 1982. "Maculatura bruna" delle pere: Eziologia e difesa. Inf. Fitopatol. 32:35-40.

Puig, M., Moragrega, C., Ruz, L., Montesinos, E., and Llorente, I. 2014 Postinfection activity of synthetic antimicrobial peptides against Stemphylium vesicarium in pear. Phytopathology 104:1192-1200.

R Core Team. 2014. R: A language and environment for statistical computing. $\mathrm{R}$ Foundation for Statistical Computing, Vienna. Online publication. http://www. R-project.org/

Singh, P., Bugiani, R., Cavanni, P., Nakajima, H., Kodama, M., Otani, H., and Kohmoto, K. 1999. Purification and biological characterization of hostspecific SV-toxins from Stemphylium vesicarium causing brown spot of European pear. Phytopathology 89:947-953.

Singh, P., Park, P., Bugiani, R., Cavanni, P., Nakajima, H., Kodama, M., Otani, H. and Kohmoto, K. 2000. Effects of host-selective SV-toxin from Stemphylium vesicarium, the cause of brown spot of European pear plants, on ultrastructure of leaf cells. J. Phytopathol. 148:87-93.

Vila, L., Lacadena, V., Fontanet, P., Martinez del Pozo, A., and San Segundo, B. 2001. A protein from the mold Aspergillus giganteus is a potent inhibitor of fungal plant pathogens. Mol. Plant-Microbe Interact. 14:1327-1331.

Vilardell, P. 1988. Stemphylium vesicarium en plantaciones de peral. Frutic. Prof. 18:51-55. 